\title{
A leitura: dos microprocessos aos macroprocessos, uma relação complementar
}

\author{
The reading: from microprocesses to macroprocesses, a complementary relation
}

La lectura: de los microprocesos a los macroprocesos, una relación complementaria

\author{
Nakita Ani Guckert Marquez $\oplus^{1}$ \\ Juliane Dutra da Rosa Silvano 1 \\ 1 Universidade do Estado de Santa Catarina. Florianópolis, SC, Brasil.
}

\begin{abstract}
RESUMO
Diante dos resultados insatisfatórios apontados pelo Programme for International Student Assessment (PISA 2015) no que se refere ao desenvolvimento da leitura de alunos brasileiros, o presente artigo traz a análise da relação complementar entre micro e macroprocessos e a sua importância no desenvolvimento da leitura competente. Para tal, baseia-se nas descobertas da psicologia cognitiva para retomar e discutir teoricamente os aspectos cognitivos envolvidos no processamento da leitura, de modo a compreender a inter-relação dos processos de decodificação e de compreensão leitora e o seu papel para o desenvolvimento de uma leitura competente. Decodificação e compreensão são aqui percebidas como processos cognitivos que se relacionam no decorrer da leitura e que, através de tal relação, podem colaborar na formação de leitores proficientes, que compreendem aquilo que leem e que fazem uso social de sua leitura.
\end{abstract}

Palavras-chave: Leitura. Processos cognitivos da leitura. Decodificação. Compreensão de leitura.

\begin{abstract}
In view of the unsatisfactory results pointed out by Programme for International Student Assessment (PISA 2015) regarding the development of reading of Brazilian students, this article is interested in analyzing the complementary relationship between micro and macroprocesses and their importance in the development of competent reading. To this end, it is based on the findings of cognitive psychology to retake and discuss theoretically the cognitive aspects involved in the processing of reading, in order to understand the interrelationship of the processes of decoding and reading comprehension and their role for the development of a competent reading. Decoding and understanding are perceived here as cognitive processes that are related in the course of reading and that, through such a relationship, can collaborate in the formation of proficient readers, who understand what they read and who make social use of their reading.
\end{abstract}

Keywords: Reading. Cognitive processes of reading. Decoding. Reading Comprehension.

\section{RESUMEN}

Ante el resultado insatisfactorio señalado por el Programme for International Student Assessment (PISA 2015) en lo que se refiere al desarrollo de la lectura de alumnos brasileños, el presente artículo se interesa por analizar la relación complementaria entre micro y macroprocesos y su importancia en el desarrollo de la lectura competente. Para ello, se basa en los descubrimientos de la psicología cognitiva para retomar y discutir teóricamente los aspectos cognitivos implicados en el procesamiento de la lectura, para comprender la interrelación de los procesos de decodificación y comprensión lectora y su papel para el desarrollo de una visión lectura competente. La decodificación y comprensión son percibidas aquí como procesos cognitivos que se relacionan en el transcurso de la lectura y que, a través de tal relación, pueden colaborar en la formación de lectores proficientes, que comprenden lo que leen y que hacen uso social de su lectura.

Palabras clave: Lectura. Procesos cognitivos de la lectura. Decodificación. Comprensión de lectura. 


\section{Introdução}

O desenvolvimento da leitura proficiente é hoje uma das grandes preocupações no âmbito escolar. Em uma sociedade grafocêntrica, o domínio eficiente do código escrito torna-se instrumento de grande importância na vida em sociedade. Porém, ainda nos deparamos com resultados insatisfatórios no que se refere à formação de leitores em nosso País. Dados do PISA 2015 apontam que os alunos brasileiros, ao concluírem o Ensino Fundamental, ainda possuem dificuldades no desenvolvimento da leitura proficiente, apresentando desempenho médio inferior à média de desempenho de estudantes de outros países, sendo que $51 \%$ dos alunos brasileiros encontram-se abaixo do nível 2 em leitura, estabelecido como o necessário para o exercício da cidadania (Pisa, 2015).

Diante de tais resultados, torna-se fundamental refletir sobre os processos cognitivos envolvidos no processamento da leitura, tanto os relacionados à decodificação, como aqueles relacionados aos processos de compreensão leitora, em uma relação complementar que possibilite o alcance da leitura proficiente, para que a mesma possa exercer a sua função social na vida do sujeito e para que, entendendo os processos cognitivos envolvidos na formação do leitor e o modo como tais processos se relacionam, possamos encontrar "respostas" aos baixos níveis dos estudantes brasileiros em leitura, apontados em avaliações nacionais de larga escala.

Nesse contexto, "saber ler e ler bem são condições indispensáveis para ler sem esforço e, assim, ter prazer em ler mais" (MORAIS, 2013, p. XXV). Esse "saber ler e ler bem" também colabora na atuação do sujeito em sociedade, na utilização de recursos como computadores e internet, no conhecimento da ciência, da tecnologia, da história e da cultura, e a ser um cidadão atuante (MORAIS, 2013). Percebe-se assim, uma perspectiva de leitura voltada para o uso social que fazemos da mesma. Porém, mesmo diante da importância dada à leitura no contexto da vida em sociedade atual, muitas crianças não alcançam o sucesso em leitura. No Brasil, a maioria dos estudantes ainda não está completamente alfabetizada ao encerrar o $4^{\circ}$ ano do Ensino Fundamental (MORAIS, 2013).

Mas o que de fato é ler? Segundo Morais (2013, p. 11) a leitura envolve um conjunto de operações mentais complexas das quais é possível converter sinais gráficos em uma representação da fala e de significado. Ao nos depararmos com uma palavra escrita desconhecida, somos capazes de lê-la, pois conseguimos recuperar a representação fonológica dessa palavra, embora, muitas vezes, não consigamos acessar o seu significado. A fim de acessarmos o significado, podemos perguntar a outra pessoa, pesquisar ou até mesmo inferir o significado baseando-se nas informações dadas pelo texto. Para alcançarmos o objetivo da leitura, que é a compreensão, precisamos aplicar às representações da fala que extraímos do texto, um conjunto de capacidades cognitivas e conhecimentos linguísticos muito variados, específicos do processo de compreender (MORAIS, 2013).

Nation (2013) também entende que o objetivo final da leitura é a compreensão. Para essa autora é preciso que o leitor disponibilize uma variedade de informações, desde habilidades lexicais até conhecimentos a respeito do mundo, para construir uma representação mental do texto.

Já para Marcuschi (2008), ler equivale a compreender, pois segundo ele a leitura acontece quando compreendemos aquilo que é lido. A leitura é vista como um ato de produção e apropriação de sentidos, inserida em um contexto social. É uma forma de agir no mundo, através da relação com o outro e dentro de um determinado contexto cultural e social. Ao se relacionar com o texto, o leitor produz sentidos, que não estão nem no leitor, nem no autor e nem no texto, mas surgem como resultado da relação entre esses componentes: texto, leitor e autor. Assim, compreender é realizar uma atividade de inferência, um processo cognitivo da atividade de compreensão textual, no qual o leitor utiliza as informações do texto considerando o contexto em que está inserido e, partindo desse ponto, realiza a construção de sentido do que lê (MARCUSCHI, 2008).

Outra definição que podemos encontrar para o que é "ler" é o modelo simples de leitura proposto por Gough e Tumner (1986), representado pela fórmula, $\mathrm{L}=\mathrm{DxC}$, na qual ler (L) é o produto de dois componentes complementares e indissociáveis, a decodificação (D) e a compreensão oral (C). Apesar do nome, esse modelo não nega a complexidade do processo de leitura, mas sim propõe que essa complexidade possa ser dividida em duas partes.

Nesse modelo o componente da decodificação é entendido como a capacidade do leitor tratar a informação gráfica que possibilitará acessar o léxico mental e recuperar a informação semântica da palavra. Já, o componente da compreensão oral/linguística é a capacidade de transformar a informação semântica ao nível da palavra em níveis mais elevados, de modo a alcançar a interpretação do discurso (HOOVER; GOUGH, 1990).

No modelo simples de leitura, tanto a decodificação como a compreensão oral são fundamentais, ambas atuam de forma interdependente para que ocorra uma leitura hábil, ou seja, se um dos componentes for igual a zero, a capacidade geral de leitura também será igual a zero. Caso um desses componentes esteja comprometido, o 
outro também sofrerá influência, impossibilitando a leitura eficiente. Assim, se uma criança não realiza bem a decodificação ou não desenvolveu habilidades de compreensão da linguagem oral, ela "não pode ler", pois uma leitura bem-sucedida exige a interação entre ambas as habilidades (SPINILLO, 2013; NATION, 2013).

Diante do exposto, este artigo objetiva explorar como os processos relacionados à decodificação podem estar vinculados aos processos de compreensão durante a leitura hábil. Para tal, pretende-se explorar/descrever como os microprocessos estão vinculados aos macroprocessos ou, dizendo de outra maneira, como estão relacionados aos objetivos de leitura. É diante dessa relação complementar que se pretende abordar no presente artigo os processos cognitivos envolvidos na leitura, de modo a compreender como os processos de decodificação (microprocessos) e de compreensão (macroprocessos) se relacionam de forma interdependente no leitor proficiente.

Apoiando-se na teoria da existência dos processos de nível inferior, ou microprocessos, correspondentes à decodificação e dos processos de nível superior, também chamados de macroprocessos, relacionados à compreensão, analisaremos a seguir os aspectos cognitivos envolvidos em cada um desses processos. Apesar de serem apresentados aqui separadamente, é importante deixar claro que esses processos agem de modo interativo e paralelo (DAS, NAGLIERI; KIRBY, 1994; LINUESA; GUTIÉRREZ, 1999, SHAYWITZ, 2003, apud CRUZ, 2007).

\section{Processos cognitivos envolvidos na decodificação}

A decodificação, ou mecanismo de reconhecimento de palavras escritas, depende de capacidades como a análise visual, a atenção, a memória e a linguagem. O domínio da decodificação implica em extrair informações suficientes das palavras de modo a ativar o léxico mental auditivo para a obtenção da informação semântica (SCLIAR-CABRAL, 2012).

Assim, o tratamento da escrita inicia-se no olho que, a cada pausa no decorrer da leitura de um texto, identifica uma ou duas palavras, extraindo o conteúdo do código escrito, através de duas vias de tratamento desse código, a via fonológica e a via lexical. A fóvea, região central da retina e única útil para a leitura, é a responsável por captar as letras e reconhecê-las. Devido à limitação biológica do olho humano, no que se refere à estreiteza da fóvea, durante a leitura é necessária a realização de movimentos oculares por sacadas (pequenos saltos), alternados por períodos de fixação. Os períodos de fixação são responsáveis por extrair a informação do texto, enquanto os movimentos sacádicos permitem ao leitor passar para outra fração do texto. Durante o percurso dos movimentos oculares pelo texto, os olhos geralmente saltam palavras gramaticais como pronomes, preposições e artigos, mas fixam-se em palavras essenciais para o conteúdo da frase, como nomes, verbos ou adjetivos. Deste modo, o centro de fixação do olho no decorrer da leitura está nas palavras de significado (DEHAENE, 2012).

Talvez esse "pousar" do olho nas palavras de significado seja um primeiro indicativo da relação existente entre os processos de decodificação e compreensão. Poder-se-ia, assim, pensar que já no decorrer do processamento ocular, o ato de ler volta-se para a extração de significado e busca a compreensão, sendo nesse ponto das fixações oculares em palavras de significado, o início da relação complementar entre os processos cognitivos da decodificação e da compreensão leitora.

Nessa etapa da decodificação, a programação biológica do ser humano entra em conflito com os traços do sistema alfabético que precisam ser reconhecidos. Biologicamente nossos neurônios estão programados para simetrizar as informações visuais, o que significa que podemos reconhecer qualquer objeto independentemente de sua posição. Contudo, para aprender um sistema de escrita alfabético é necessário fazer uma reciclagem neuronal ensinando aos neurônios a dissimetrizar. Só assim o cérebro conseguirá distinguir a direção dos traços das letras, e reconhecer a diferença existente entre as letras "b", "d", "q" e "p", por exemplo (DEHAENE, 2012; SCLIAR-CABRAL, 2015).

Durante o processo de decodificação além da dimensão perceptiva, temos também a dimensão lexical, ou seja, é necessário recuperar o significado da palavra no léxico mental auditivo. É a conexão entre o conhecimento linguístico do leitor e a representação gráfica da palavra extraída do texto que permite ao leitor chegar ao significado.

Considera-se a existência de duas vias possíveis para chegarmos ao reconhecimento da palavra escrita e extrairmos o seu significado: a via fonológica ou a via lexical. A via fonológica consiste na identificação das palavras por meio da aplicação das regras de conversão grafema-fonema. Ao identificar as letras, realiza-se a correspondência grafema-fonema para a recuperação da pronúncia da palavra, que posteriormente acessa o léxico mental auditivo, que por sua vez ativa o sistema semântico, recuperando assim, o significado da palavra (COLTHEART, 2013).

A outra via para acesso ao léxico mental é lexical, também denominada de via direta. Essa via consiste em enviar a análise visual da palavra escrita para um armazém de representações ortográficas que compara essa palavra com as já armazenadas ali, identificando-a e ativando o 
seu significado no sistema semântico (MORAIS, 1997; CUETOS VEGA, 2002).

É importante deixar claro que, apesar de distintas, essas duas vias de leitura agem de forma mutuamente compensatória. Além disso, ambas trabalham em função do desenvolvimento da leitura fluente que, por sua vez, permitirá voltar a atenção e os recursos cognitivos do leitor para os processos de compreensão leitora. A escolha de qual via de leitura será utilizada pelo leitor vai depender das habilidades desse leitor e das características da palavra a ser lida. A via fonológica é preferencialmente utilizada pelo leitor aprendiz, pois este ainda não construiu um léxico mental ortográfico robusto para que possa reconhecer as palavras escritas automaticamente, e também é utilizada pelos leitores habilidosos para ler palavras pouco frequentes e desconhecidas. Isso significa que para que ocorra uma leitura competente é necessária a atuação das duas vias de leitura (ELLIS, 1995; CORSO; SALLES, 2009).

\section{Processos cognitivos envolvidos na compreensão}

A compreensão do que se lê é o objetivo da leitura. Ela não tem um circuito neural específico, é a mesma para a compreensão de uma conversa ou de um filme, o que a diferencia são os materiais a manipular e as decisões sobre as intervenções a realizar. Requer também um conjunto de capacidades e conhecimentos cognitivos e linguísticos: capacidades cognitivas gerais como atenção, conhecimentos prévios, memória de trabalho e relacionamento de informações; e capacidades e conhecimentos linguísticos, como conhecimento sobre vocabulário, interpretação de expressões metafóricas, estrutura sintática, construção de sentido e ligar cada frase a frase seguinte (MORAIS, 2013).

A compreensão leitora se constitui no processo de elaboração progressiva de uma representação mental por meio da integração das informações fornecidas pelo texto, de modo que as intenções do autor sejam adequadamente percebidas e a coerência do texto seja preservada. Nesse processo atuam diversas capacidades cognitivas, como manter a atenção no que se lê, recuperar os conhecimentos prévios, manter as informações fornecidas pelo texto na memória de trabalho, relacionar as informações que estão em diferentes partes dos textos para atribuir-lhes um sentido e fazer inferências. Assim, através do processo de compreensão a informação do texto é "sintetizada e integrada" aos conhecimentos prévios do próprio leitor (MORAIS, 2013; CORSO; SPERB; SALLES, 2013).

Existem três variáveis que estão envolvidas no processo de compreensão: o leitor, o texto e o contexto. $\mathrm{Na}$ variável leitor estão envolvidas as estruturas do sujeito e os processos de leitura que ele utiliza. O leitor é a variável mais complexa do modelo de compreensão, e onde de fato ocorre o processo cognitivo de compreensão. Ele utiliza as suas estruturas cognitivas e afetivas na atividade de leitura e recorre também a diferentes processos que lhe auxiliam na compreensão do texto. As variáveis texto (material a ler, a intenção do autor, a estrutura do texto e o conteúdo) e contexto (onde o texto se insere) influenciam nesse processo de compreensão realizado pelo leitor. Quanto mais essas variáveis estiverem ligadas umas às outras, melhor será a compreensão (GIASSON, 1993; MARCUSCHI, 2008).

Kintsch e Van Dijk, propõem um modelo de processamento de texto que descreve passo a passo como o leitor elabora a compreensão textual. Nesse modelo a compreensão é construída estrategicamente, por meio de níveis de processamento e de representação diversos, que agem simultaneamente (KINTSCH; RAWSON, 2013). O processamento diz respeito à forma como as informações se transformam em ideias, através das proposições, e a representação refere-se à diferentes níveis da construção da representação de texto (COELHO; CORREA, 2017).

No modelo de Kintsch e Van Dijk (1978), o nível inicial de processamento do texto, seria o de processamento de palavras e frases. O leitor precisaria inicialmente decodificar símbolos gráficos (reconhecer palavras), momento no qual estão envolvidos processos perceptivos e análise gramatical das palavras. É a análise semântica que irá determinar o significado do texto. Os significados das palavras se combinam gerando ideias ou proposições. Essas proposições são inter-relacionadas em uma rede, criando as chamadas microestruturas. Essa microestrutura não é garantia de acesso ao significado do texto, é preciso que durante a leitura os significados das palavras e a microestrutura se organizem dentro da macroestrutura do texto, ou seja, uma estrutura mais global. Macroestrutura e microestrutura formam juntas o que chamam de "texto-base", que conduz ao significado do texto, o entendimento do conteúdo que está explícito no texto, mas esse entendimento possibilita uma compreensão superficial. Para chegarmos à compreensão completa é preciso ir além do que está explícito no texto, criar um modelo situacional, isto é, um modelo mental da situação que está descrita no texto. Para isso, é preciso que o leitor integre as informações recebidas do texto com os seus conhecimentos prévios de mundo e com os objetivos propostos para a leitura (CORSO; SPERB; SALLES, 2013; KINTSCH; RAWSON, 2013).

O modelo situacional permite que o leitor busque informações para estabelecer a coerência do texto, incluindo a esse processo os conhecimentos prévios de mundo. Enquanto o leitor constrói o texto base ele vai comparando-o com o modelo situacional, logo 
a compreensão depende tanto da construção de uma representação textual, como também da representação do contexto social ao qual o texto remete (FARIAS, 2000).

Assim, Giasson (1993) considera cinco categorias de processos cognitivos envolvidos na compreensão de leitura: 1) microprocessos, servem para compreender informações contidas em uma determinada frase (reconhecimento de palavras, leitura de grupos de palavras, microsseleção); 2) processos de integração, para fazer ligações entre proposições ou frases (utilização de referentes e conectores, inferências baseadas em esquemas); 3) Macroprocessos, ligados à compreensão global do texto (identificar ideias principais, resumo, utilizar estrutura do texto); 4) processos de elaboração, para ir além do texto, fazer inferências (previsões, imagens mentais, resposta afetiva, ligação com conhecimentos, raciocínio); e 5) processos metacognitivos, para gerir compreensão e fazer com que leitor consiga se adaptar ao texto e à situação (identificar perda de compreensão, reparar a perda de compreensão) (GIASSON, 1993).

No que se refere à compreensão textual os conhecimentos prévios são aquelas informações necessárias que o leitor precisa ter para que consiga compreender um texto sem muita dificuldade. Para que o leitor alcance a compreensão textual é necessário ativar os seus conhecimentos de mundo, linguísticos e textuais de forma que a integração desses conhecimentos o permita fazer inferências e construir o sentido do texto (KLEIMAN, 2008).

Deste modo, destaca-se o aspecto sociocultural da compreensão leitora e a importância da realização de inferências. Nem tudo que quer ser dito está escrito no texto de maneira objetiva, sendo a atividade de compreensão de texto praticamente uma atividade de coautoria. Um texto não é um produto acabado e objetivo, é um evento comunicativo, uma atividade colaborativa que acontece na relação entre autor-texto-leitor, e por isso está constantemente em elaboração. Os sentidos são produzidos pelos leitores na relação com o texto e o contexto social, cultural e histórico. Desse modo, os sentidos de um texto em parte estão no texto e em parte serão completados pelo leitor. Para compreender partimos dos conhecimentos e informações trazidos pelo texto, e dos nossos conhecimentos pessoais, de modo a produzir/ inferir sentidos sobre o que se lê (MARCUSCHI, 2008).

Poderíamos por fim reivindicar que a compreensão se constitui de processos ascendentes e descendentes. Os processos ascendentes (bottom-up) corresponderiam àqueles que, por meio dos significados das palavras, proposições e inferências, constroem uma rede de significados que se integra a uma estrutura global. E os processos descendentes (top-down) são aqueles que guiam a leitura e contribuem para a sua significação (CORSO; SPERB; SALLES, 2013).

\section{A interdependência dos processos cognitivos}

Diante do exposto sobre cada um dos processos cognitivos aqui abordados, percebe-se que, dentre as categorias envolvidas no processo de compreensão, destaca-se a presença dos microprocessos ou processos de microestrutura, relacionados aos processos de reconhecimento de palavras/ decodificação, que aparecem no início do caminho que leva aos macroprocessos ou processos de macroestrutura, ou seja, processos de compreensão global do texto. Desse modo, até mesmo no modelo de compreensão de leitura, a decodificação aparece como ponto de partida que levará ao alcance da compreensão, evidenciando a relação estabelecida entre ambos os processos no decorrer da leitura no leitor proficiente.

A automatização e a rapidez no processo de reconhecimento de palavras escritas são fundamentais para que o leitor possa alcançar a compreensão textual. Busca-se a automatização dos processos de baixo nível ou de microestrutura/microprocessos, para que o leitor possa voltar a sua atenção, os seus recursos cognitivos e o espaço na memória de trabalho para os processos de alto nível/macroestrutura/macroprocessos, estabelecendo uma relação de complementaridade entre eles. Ou seja, a atenção consciente do leitor pode voltar-se para aquilo que não pode ser automático: o processo de compreensão (CATALÀ et al., 2001; GIASSON, 1993; MORAIS, 2013).

Sternberg e Grigorenko (2003) formularam um modelo de desenvolvimento de leitura que menciona a importância da automatização do processo de decodificação para que o leitor possa utilizar estratégias metacognitivas para a compreensão textual, como voltar a atenção para a utilização do seu conhecimento prévio e do propósito de sua leitura, por exemplo (CORSO; SALES, 2009).

Um estudo de Perfetti (1985) afirmou que quando a decodificação é lenta os recursos cognitivos dedicam-se aos processos de nível inferior e quando está automatizada os recursos são disponibilizados para o processamento da compreensão. Crianças mais lentas em decodificação são as que mais apresentavam problemas de compreensão, estendendo-se essa dificuldade até a vida adulta.

Perfetti (1992) observou também que leitores com dificuldade em decodificação, ao ler, dependiam mais do contexto do material que estava sendo lido, como forma de compensar as suas dificuldades e conseguir reconhecer as palavras escritas. Diante disso, poderiam também estar 
os componentes do processo de compreensão auxiliando no processo de decodificação.

Um estudo de Corso e Sales (2009) realizado com 110 crianças do 2o ano do Ensino Fundamental, com o objetivo de verificar se era possível o leitor com pouca habilidade de decodificação ter uma boa compreensão textual, constatou que todas as crianças com baixos escores em decodificação apresentavam déficits na compreensão textual, sugerindo que crianças com bons níveis de compreensão textual têm boas habilidades de reconhecimento de palavras. O estudo também apontou crianças com boas habilidades no reconhecimento de palavras, mas com baixo nível de compreensão textual, indicando que essas dificuldades advinham especificamente da compreensão. Ou seja, a habilidade de reconhecimento de palavras é essencial para uma boa compreensão textual, embora não seja garantia para tal, podendo a dificuldade estar em algum componente específico do processo de compreensão, apesar que isso seja mais difícil de ocorrer e de ser identificado. Apenas $10 \%$ das crianças em idade escolar têm dificuldades específicas de compreensão, que não estão relacionadas com a dificuldade em decodificação (CLARKE, 2010).

As dificuldades específicas de compreensão podem estar relacionadas a uma série de distúrbios de linguagem, como compreensão auditiva, vocabulário, expressão oral, linguagem figurativa e gramática, demonstrando dificuldades em níveis mais elevados de processamento, como na capacidade de fazer inferências e monitorar a compreensão (CLARKE, 2010; NATION, 2013).

Com o avanço da escolaridade espera-se que a leitura passe a depender mais da compreensão e menos da decodificação, pois os leitores já automatizaram as correspondências grafema-fonema, abrindo espaço para as atribuições de significado. Quando as crianças se tornam competentes em decodificação, sua competência na compreensão é que determinará sua capacidade geral de leitura. Por isso nos primeiros anos de escolaridade as crianças precisam estabelecer uma leitura fluente e automática de palavras, o que, isoladamente, não é o suficiente para uma leitura proficiente, mas é necessário. A capacidade de compreender continuará a se desenvolver durante toda a vida adulta. Logo, em uma leitura mais avançada a compreensão será mais crucial do que o reconhecimento de palavras (SPINILLO, 2013; OAKHILL; CAIN; ELBRO, 2015).

De acordo com um estudo de Hoover e Gough (1990) realizado com crianças da $1^{\underline{a}}$ série à $4 \underline{a}$ árie do Ensino Fundamental (nomenclatura utilizada na época), com o objetivo de identificar a correlação e a importância dos componentes da decodificação e da compreensão oral para a compreensão de leitura, constatou-se uma contribuição relativamente mais forte da decodificação nas duas primeiras séries de escolaridade e da compreensão oral nas duas últimas séries.

Outros estudos (CURTIS 1980; JACKSON; MCCLELLAND 1979; PALMER; MACLEOD; HUNT; DAVIDSON 1985; SINGER, CROUSE 1981; STANOVICH; CUNNINGHAM; FEEMAN, 1984; STANOVICH; NATHAN, VALA-ROSSI, 1986, apud HOOVER; GOUGH, 1990) corroboram com os achados de Hoover e Gough (1990) indicando que nas séries iniciais, as habilidades de decodificação e compreensão oral correlacionam-se com a compreensão de leitura, tendo a decodificação um coeficiente mais expressivo, cerca de 0,55 , em relação a compreensão oral, com um coeficiente médio de 0,35 . Já nas séries finais ocorre o inverso, sendo o componente mais expressivo para a compreensão de leitura a compreensão linguística.

Para ilustrar a complexidade e a inter-relação existente entre os processos cognitivos envolvidos na leitura, trazemos a imagem da corda elaborada por Scarborough (2001) (Figura 1).

Figura 1 - Competências de leitura segundo Scarborough (2001)

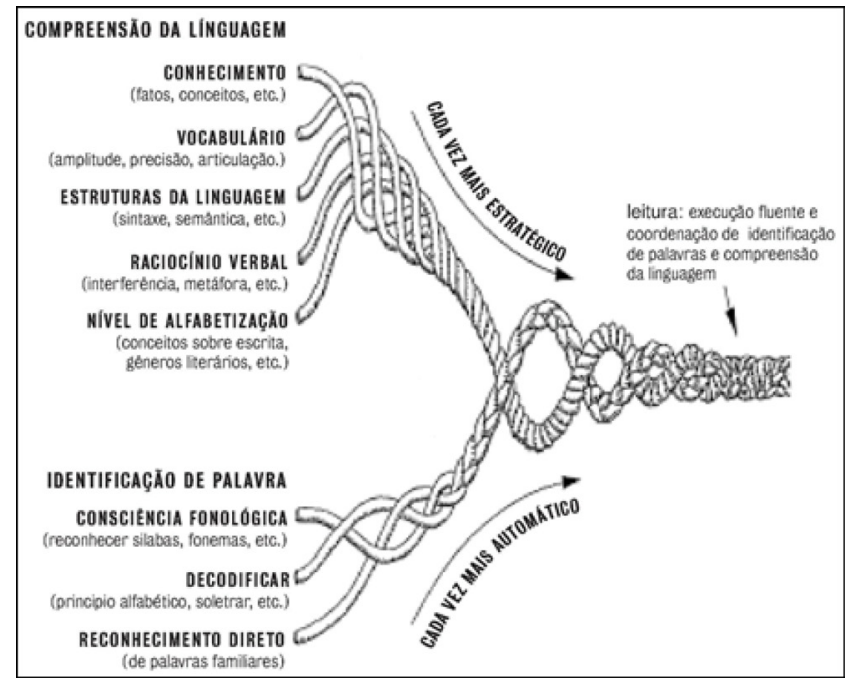

Fonte: Grupo de trabalho alfabetização infantil: os novos caminhos: relatório final, 2003

Um dos ramos da corda, o que está na parte inferior esquerda, corresponde aos microprocessos, o processo de reconhecimento de palavras, que ao longo do processo de alfabetização deve se dar cada vez de forma mais automática. Esse componente dependente do desenvolvimento da consciência fonológica, da descoberta do princípio alfabético, da automatização das correspondências grafema-fonema e da construção de um léxico mental vocabular que possibilite o reconhecimento imediato das palavras.

No ramo superior esquerdo da corda, encontra-se os macroprocessos, o componente da compreensão oral, 
que ao longo do processo de alfabetização deve se tornar cada vez mais estratégico. Esse componente dependerá de diversos conhecimentos, como o conhecimento a respeito do mundo, do vocabulário, das estruturas de linguagem e estruturas textuais além da capacidade de raciocínio verbal, como fazer inferências e compreender anáforas.

É o resultado da atuação eficiente desses componentes e da sua inter-relação que possibilitará ao leitor alcançar uma leitura fluente, com o alcance da automaticidade dos processos de decodificação e com o desenvolvimento cada vez mais estratégico dos processos de compreensão, para então fazer o uso social da leitura rumo à sua formação cidadã.

\section{Considerações finais}

Diante dos baixos níveis de competência em leitura expostos pelo Pisa 2015 é necessário atentar para a identificação das origens das dificuldades de leitura dos alunos, verificando se elas se encontram no âmbito dos processos de decodificação ou de compreensão.

Primeiramente é importante perceber que a aprendizagem da leitura não acontece "naturalmente" para a criança, apenas no contato com um ambiente alfabetizado. É um erro pensar que, para desenvolver competências de leitura, basta o leitor iniciante ser ensinado a decodificar palavras escritas, que suas habilidades de compreensão se desenvolverão automaticamente. Assim, é essencial a preocupação com o ensino explícito da decodificação e da compreensão de leitura, voltando a atenção para os processos cognitivos que envolvem ambas as habilidades, de maneira que se complementem na formação de leitores proficientes, que sejam capazes de ler e compreender aquilo que leem de maneira fluente.

Ambos os componentes da leitura, da decodificação e da compreensão, estabelecem forte relação entre si no decorrer do desenvolvimento da aprendizagem da leitura. Desde os movimentos oculares, ainda no campo da percepção das letras e dos traços, a leitura já busca focarse nas palavras de significado, de modo a ter por objetivo a possibilidade de alcance da compreensão. Dessa forma, a decodificação já seria guiada rumo à compreensão leitora, desde o momento da percepção das letras e do reconhecimento de palavras, buscando o acesso ao léxico mental e, consequentemente, ao significado.

M É importante deixar claro, no entanto, que no leitor iniciante isso não ocorre de forma automática, pois para realizar a leitura pela via lexical é necessário primeiramente construir um léxico mental, ou seja, o leitor precisa "tratar" o material, construir e automatizar um mecanismo de reconhecimento de palavras escritas que o possibilite, ao menos, acessar o léxico da linguagem oral ou transformar os sinais gráficos em uma representação de fala. Por isso, a importância da automatização das correspondências grafema-fonema, para que os espaços e os recursos cognitivos aplicados à aprendizagem da decodificação, nessa fase ainda inicial da alfabetização, possam ser liberados para que o leitor volte sua atenção aos processos de compreensão.

Essa distinção nos leva a refletir sobre os modos de ensino-aprendizagem da leitura. É necessário que os professores compreendam como atuam os processos cognitivos envolvidos na leitura, de modo que construam práticas pedagógicas que promovam a aprendizagem efetiva do reconhecimento de palavras, possibilitando a inter-relação entre a decodificação e a compreensão, para que assim os leitores possam alcançar o objetivo final da leitura, que é a compreensão e, consequentemente, o uso social do que se lê.

Para que a leitura de fato possa ser utilizada pelo sujeito nessas suas interações sociais, é necessário que ele desenvolva a capacidade de compreender em profundidade aquilo que lê, fazendo uso de inferências, previsões e conclusões. Sem essa habilidade o leitor será capaz apenas de decodificar, sem extrair significado das palavras reconhecidas. É por este motivo que se destaca aqui a importância da relação complementar entre os processos de decodificação e compreensão, pois é através da qualidade desta relação que formar-se-á o leitor competente, aquele que lê, compreende e faz uso social de sua leitura.

\section{Referências}

BRASIL. Câmara dos Deputados. Comissão de Educação e Cultura. Relatório final do Grupo de trabalho alfabetização infantil: os novos caminhos. Brasília: Câmara dos Deputados, 2003. Disponível em: http://www2.camara.leg.br/ atividade-legislativa/comissoes/comissoes-permanentes/ce/ documentos-1/relatorio-de-atividades/Relat Final.pdf. Acesso em: 08 out. 2018.

CATALÀ, Glória et al. Evaluación de la comprensión lectora: pruebas ACL ( $11^{\mathrm{O}}-6^{\mathrm{o}}$ de primaria). Madrid: Graó, 2001.

CLARKE, Paula et al. Ameliorating children's readingcomprehension difficulties: a randomized controlled trial. Psychological Science, New York, v. 21, n. 8, p. 1106-1116, Aug. 2010. https://doi.org/10.1177/0956797610375449

COELHO, Carmen Lucia Gobel; CORREA, Jane. Compreensão de leitura: habilidades cognitivas e tipos de texto. Psico, Porto Alegre, v. 48, n. 1, p.40-49, 2017. https:// doi.org/10.15448/1980-8623.2017.1.23417

COLTHEART, Max. Modelando a leitura: a abordagem da dupla rota. In: SNOWLING, Margaret J.; HULME, Charles (org.). A ciência da leitura. Porto Alegre: Penso, 2013. p. 24-41. 
CORSO, Helena Vellinho; SPERB, Tânia Mara; SALLES, Jerusa Fumagalli de. Compreensão leitora: modelos de processamento e relações com outras habilidades cognitivas. In: ROAZZI, Antônio; JUSTI, Francis Ricardo dos Reis; SALLES, Jerusa Fumagalli (org.). A aprendizagem da leitura e da escrita: contribuições de pesquisas. São Paulo: Vetor, 2013. p. 83-108.

CORSO, Helena Vellinho; SALLES, Jerusa Fumagalli de. Relação entre leitura de palavras isoladas e compreensão de leitura textual em crianças. Letras de Hoje, Porto Alegre, v. 44, n. 3, p. 28-35, jul./set. 2009.

CRUZ, Vitor. Abordagem cognitiva da leitura. Lisboa: Lidel, 2007.

CUETOS VEGA, Fernando. Psicología de la lectura: diagnóstico y tratamiento de los transtornos de lectura. Madrid: Cisspraxis, 2002.

DEHAENE, Stanislas. Os neurônios da leitura: como a ciência explica a nossa capacidade de ler. Tradução de Leonor Cabral. Porto Alegre: Penso, 2012.

ELLIS, Andrew W. Leitura, escrita e dislexia: uma análise cognitiva. Tradução de Dayse Batista. 2. ed. Porto Alegre: Artes Médicas, 1995.

FARIAS, Washington Silva da. Compreensão e resumo de textos: alguns aspectos teóricos e experimentais. Revista de Letras, Fortaleza, v. 1/2, n. 22, p. 103-110, jan./dez. 2000.

GIASSON, Jocelyne. A compreensão na leitura. Portugal: Asa, 1993

GOUGH, Philip B.; TUNMER, William E. Decoding, reading, and reading disability. Remedial and Special Education, [s. l.], v. 7, n. 1, p. 6-10, Jan. 1986. https://doi. org/10.1177/074193258600700104

HOOVER, Wesley; GOUGH, Philip B. The simple view of reading. Reading and Writing, [s. l.], v. 2, n. 2, p. 127-160, June 1990. https://doi.org/10.1007/BF00401799

KINTSCH, Walter; RAWSON, Katherine A. Compreensão. In: SNOWLING, Margaret J.; HULME, Charles (org.). A ciência da leitura. Porto Alegre: Penso, 2013. p. 227-244.

KLEIMAN, Angela. Texto e leitor: aspectos cognitivos da leitura. Campinas: Pontes, 2008.

MARCUSCHI, Luiz Antônio. Produção textual, análise de gêneros e compreensão. São Paulo: Parábola Editorial, 2008.

MORAIS, José. A arte de ler: psicologia cognitiva da leitura. Lisboa: Edição Cosmos, 1997.

MORAIS, José. Criar leitores: para professores e educadores. Barueri: Manole, 2013.

NATION, Kate. Dificuldades de compreensão da leitura em crianças. In: SNOWLING, Margaret J.; HULME, Charles (org.). A ciência da leitura. Porto Alegre: Penso, 2013. p. 266283.

OAKHILL, Jane; CAIN, Kate; ELBRO, Carsten. Understanding and teaching reading comprehension: a handbook. London: Routledge, 2015. https://doi. org/10.4324/9781315756042

\section{ORGANIZAÇÃO PARA A COOPERAÇÃO E} DESENVOLVIMENTO ECONÔMICO. Brasil no PISA 2015: análises e reflexões sobre o desempenho dos estudantes brasileiros. São Paulo: Fundação Santillana, 2016.

PERFETTI, Charles A. A capacidade para a leitura. In: STERNBERG, R. (org.) As capacidades intelectuais humanas: uma abordagem em processamento de informações. Porto Alegre: Artes Médicas, 1992. p. 72-96.

PERFETTI, Charles A. Reading ability. New York: Oxford University Press, 1985.

SCARBOROUGH, Hollis. A. Connecting early language and literacy to later reading (dis)abilities. Evidence theory and practice. In: NEUMAN, Susan B.; DICKINSON, David K. (ed.). Handbook of research in early literacy. New York: Guilford Press, 2001.

SCLIAR-CABRAL, Leonor. Sistema Scliar de alfabetização: fundamentos. Florianópolis: Lili, 2012.

SCLIAR-CABRAL, Leonor. Pela melhoria na qualidade da alfabetização. Revista Estudos Legislativos, Porto Alegre, v. 9, n. 9, p. 21-38, 2015.

SPINILLO, Alina Galvão. Alfabetização e consciência metalinguística: da leitura da palavra à leitura do texto. In: MALUF, Maria Regina; CARDOSO-MARTINS, Cláudia (org.). Alfabetização no século XXI: como se aprende a ler e a escrever. Porto Alegre: Penso, 2013. p.138-154.

Recebido em: 29/10/2018.

Aprovado em: 22/5/2019.

Publicado em: 5/11/2019.

\footnotetext{
Autoras:

Nakita Ani Guckert Marouez

Mestra pela Universidade do Estado de Santa Catarina, Florianópolis, Brasil. Graduada em Pedagogia, especialista em Psicopedagogia Clínica e Institucional e em Práticas Pedagógicas Interdisciplinares. Professora do Instituto Federal Catarinense, Rio do Sul, SC, Brasil. Orcid: https://orcid.org/0000-0001-9055-5613

E-mail: nakita.marquez@ifc.edu.br

Juliane Dutra da Rosa Silvano

Mestranda da Universidade do Estado de Santa Catarina, Florianópolis, Brasil. Graduada em Pedagogia, com habilitação em Séries Iniciais, especialista em Educação e Estudos Culturais e em Planejamento, Implementação e Gestão da Educação a Distância. Pedagoga da Força Aérea Brasileira.

Orcid: https://orcid.org/0000-0003-2645-3406

E-mail: juli dutradarosa@hotmail.com

Endereço: Āv. Me. Benvenuta, 2007 - Itacorubi 88035-901, Florianópolis, SC, Brasil
} 